\title{
The Thrombolytic and Cytotoxic Effects of Nigella sativa (L.) Seeds: The Prophetic Medicine
}

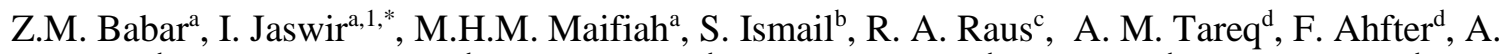 \\ Faraque $^{\mathrm{d}, \mathrm{e}}$, A.S.M Ali Reza ${ }^{\mathrm{d}}$, M. A. Sayeed ${ }^{\mathrm{d}}$, Md. M. Hossain ${ }^{\mathrm{d}}$, M. Uddin ${ }^{\mathrm{d}}$, M. S. Hossain ${ }^{\mathrm{d}}$, S.

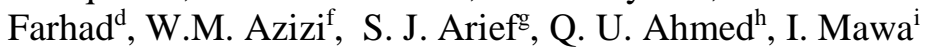 \\ anternational Institute for Halal Research and Training (INHART), International Islamic University Malaysia, Level 3, KICT Building, Jalan Gombak, \\ 53100 Selangor, Malaysia \\ ${ }^{b}$ Department of Basic Medical Sciences, Faculty of Medicine, International Islamic University Malaysia, Level 3, 53100 Selangor, Malaysia \\ ${ }^{c}$ Department of Biotechnology, Faculty of Engineering, International Islamic University Malaysia, Level 3, 53100 Selangor, Malaysia \\ ${ }^{\mathrm{d}}$ Department of Pharmacy, International Islamic University Chittagong, Kumira, Chittagong-4318, Bangladesh \\ ${ }^{\mathrm{e}}$ School of Food Science and Engineering, South China University of Technology, Wuchan Campus, Building 32, Guangzhou, Guangdong, 510640, China \\ ${ }^{\mathrm{f}}$ Kolej Universiti Antarabangsa PICOMS (PIUC), Taman Batu Muda, 3, Jalan 31/10a, Taman Perindustrian Iks, 68100 Kuala Lumpur, Wilayah Persekutuan \\ Kuala Lumpur, Malaysia \\ ${ }_{\mathrm{g}}^{\mathrm{g}}$ Faculty of Dentistry, International Islamic University Malaysia, Jalan Hj. Ahmad Shah, Bandar Indera Mahkota, 25200 Kuantan, Pahang, Malaysia. \\ ${ }^{h}$ Department of Pharmaceutical Chemistry, Faculty of Pharmacy, International Islamic University Malaysia, Jalan Hj. Ahmad Shah, Bandar Indera Mahkota, \\ 25200 Kuantan, Pahang, Malaysia. \\ ¿Department of Microbiology, University of Science and Technology Chittagong, Zakir Hossain Road, Foy’s Lake, Khulshi, Chittagong 4202, Bangladesh. \\ 1 irwandi@iium.edu.my \\ * corresponding author
}

ARTICLE INFO

Article history

Received June 25, 2020

Revised August 10, 2020

Accepted November 13, 2020

Keywords:

Brine Shrimp Nauplii (Artemia salina)

Cytotoxicity

Human Blood Clot

Thrombolysis

Water-Soluble Extract (WSE)

\section{ABSTRACT}

The Water-Soluble Extract (WSE) is a crude bioactive phytoconstituent of Nigella sativa (L.) seeds discovered recently. The current findings report about the thrombolytic and cytotoxic effects of WSE using human blood clot lysis and brine shrimp lethality (BSL) bioassay. The thrombolytic effect of WSE $(1,666.67 \mu \mathrm{g} / \mathrm{mL})$ was determined via the clot and lysate weight measurements compared to streptokinase (STK) of $30,000 \mathrm{IU} / \mathrm{mL}$ and normal saline (NS) while the cytotoxicity of WSE $(44.14-2,000 \mu \mathrm{g} / \mathrm{mL})$ against vincristine sulfate (VCS;3.125-100 $\mu \mathrm{g} / \mathrm{mL})$. WSE has shown extremely statistically significant $(\mathrm{p}<0.0001)$ clot lysis $(90.00 \%)$ compared to NS $(3.76 \%)$ whilst it was also significantly different $(\mathrm{p}<0.0063)$ to STK $(72.41 \%)$ exhibiting $\mathrm{LC}_{50}$ of $1,795.90 \mu \mathrm{g} / \mathrm{mL} v s$. VCS $(39.25 \mu \mathrm{g} / \mathrm{mL})$ in a dose-dependent manner. The current results suggested WSE has a potent thrombolytic effect with mild dose-dependent cytotoxicity towards brine shrimp nauplii (Artemia salina). It also suggested WSE might have enzymatic roles on thrombin, fibrin, and plasmin of blood. This pharmacological action of WSE is might be due to its antioxidant property, short-chain fatty acids and/or amino acids. Further studies are highly recommended on the enzymatic role(s) and bioactive phytoconstituents of WSE.

This is an open access article under the CC-BY-SA license.

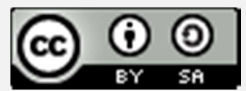

\section{Introduction}

Nigella sativa ( $N$. sativa) is an annual flowering herb of the Ranunculaceae family and genus Nigella which has 18 species, native to South and Southwest Asia, Southern Europe, and North Africa. Since 1880, numerous studies had been conducted on its bioactivities including thrombolytic and fibrinolytic properties (Awad and Binder, 2005; Asgary et al., 2012; Lebda et al., 2012). Since time immemorial, $N$. sativa (L.) seeds had been used traditionally in Unani, Tibb, Ayurveda, Siddha, and Arabic medicines (Ahmad et al., 2013). Primarily, it is composed of fixed 
oil $(\leq 38 \%)$, essential oil $(\leq 1.5 \%)$, dietary protein $(\leq 26.7 \%)$, fat $(\leq 28.5 \%)$, and carbohydrate $(\leq 40 \%)$. In its essential oil, thymoquinone (TQ), the so-called most bioactive compound was reportedly found up to $48 \%$ whilst other bioactives include t-anethole (4\%), 4-terpineol $(7 \%)$, sesquiterpene longifolene (8\%), carvacrol (12\%), p-cymene (15\%), thymol, dihydrothymoquinone (DTQ) and thymohydroquinone (THQ). In fixed oil, it was reported to contain mainly linoleic acid $(65 \%)$, oleic acid (24\%), palmitic acid (20\%), dihomolinoleic acid (10\%) and eicosadienoic acid (3\%) and many fatty acids including sterol esters and glycosides (Ahmad et al., 2013; Al-Jassir, 1992; Houghton et al., 1995; Cheikh-Rouhou et al., 2007; Gholamnezhad et al., 2016).

The WSE was found to be highly polar by nature with solubility in both $5 \% \mathrm{NaOH}$ and $\mathrm{HCl}$ solutions which might be an indication of a wide range of solubility or therapeutic index with active $\delta+$ and $\delta-$ sites. It has also shown more than two-fold stronger antioxidant capacity than its fixed oil (Babar et al., 2019a).

Thrombolytic or fibrinolytic drugs are being used to treat coronary artery disease, deep vein thrombosis, myocardial infarction, strokes, and pulmonary embolism, etc. Most of the thrombolytic drugs target the fibrin, one of the main constituents of a blood clot to lyse the clot (Babar et al., 2019a; Dewan and Das, 2013). Fibrin, thrombin, and plasmin play vital roles individually and/or collectively in blood coagulation, thrombosis, and hemostasis while various enzymes, cofactors, and receptors, such as serine protease, cofactor V and VIII and protease-activated receptors (PARs) are also involved respectively (Tanaka et al., 2009; Ali et al., 2014; Chapin and Hajjar, 2015).

Cytotoxicity of thymoquinone, essential oil, and different fractions of $N$. sativa (L.) seeds has been studied extensively but there was no such report about WSE. A recent study conducted on the cytotoxicity of various fractions (i.e., petroleum ether, ether, methanol, chloroform, and water) and essential oil of $N$. sativa on brine shrimp through the paper disc and solution methods found petroleum ether and chloroform to be the most cytotoxic with LC50 of 7 and $21 \mu \mathrm{g} / \mathrm{mL}$ respectively whilst the aqueous fraction has shown insignificant cytotoxicity for the above two methods (Mahmoudvand et al., 2017). Therefore, the current study was aimed to investigate the thrombolytic (i.e., \% clot lysis) and cytotoxic (i.e., \% mortality) effects of WSE using human blood clot lysis and brine shrimp lethality (BSL) assays respectively.

\section{Materials and methods}

\subsection{Extraction and yield of WSE}

The detailed process of extraction and yield of WSE has been discussed in our earlier report (Babar et al., 2019a). This is the preliminary study of our recent study (Babar et al., 2019b) on WSE, which was preserved at $3 \pm 1^{\circ} \mathrm{C}$ in a Falcon ${ }^{\circledR}$ tube $(50 \mathrm{~mL})$ wrapped with aluminium foil. It was noted that $1 \mu \mathrm{L}$ contains $\approx 0.88 \mathrm{mg}(\mathrm{w} / \mathrm{v})$ of WSE. A significant amount $(\approx 15 \mathrm{~g})$ of WSE was sent safely to the Department of Pharmacy, International Islamic University Chittagong (IIUC), Bangladesh from Kuala Lumpur. Upon arrival at the mentioned institution, the sample was kept at $4{ }^{\circ} \mathrm{C}$ until use.

\subsection{Ethical consideration}

As the current study is a part and preliminary experiment of our recent study (Babar et al., 2019b), thus, this study protocol was also approved by the Institutional Ethics Committee (IEC) of the Department of Pharmacy, IIUC under the same reference (Pharm/PND/138/13\#2019).

\subsection{Guidelines}

The current study has strictly followed and maintained the recommendations (v 1.1, June 2018) of the European Federation of Clinical Chemistry and Laboratory Medicine (EFLM) on the best practices of venous blood sampling (Simundic et al., 2018). For hatching the brine shrimp nauplii, the notes and instructions of 'Ocean Nutrition Americas', was followed. 


\subsection{Materials}

The stabilized pure streptokinase (STK® Inj.; 1.5 million IU) vial in powder form produced by Incepta Pharmaceuticals Ltd., Sodium Chloride BP 0.9\% w/v and Dextrose 5\% USP w/v solution (Solodex ${ }^{\mathrm{TM}}$ IV Infusion) manufactured by Square Pharmaceuticals Ltd., Bangladesh, and two vials of vincristine sulfate (Criston 2, 2mg/2mL; Beacon Pharmaceutical Ltd., Bangladesh) were bought from a local pharmacy shop in Chittagong. The $50 \mathrm{~g}$ of brine shrimp of 'S.K Artemia Cysts' brand imported from Thailand was purchased from a local supplier in Cox's Bazar. The portable aeration pump (Brand: Amplab Bangladesh) with a single air-flow was purchased from the online shopping site (www.daraz.com.bd).

\subsection{WSE stock and working solutions preparation}

A stock solution of WSE $(10,000 \mu \mathrm{g} / \mathrm{mL})$ was prepared by adding $125 \mu \mathrm{L}$ of WSE into $11 \mathrm{~mL}$ of normal saline (NS) water for both thrombolytic and cytotoxic studies, and 12 random $5 \mathrm{x}$ concentrations of aliquots (i.e., $5 \mathrm{x} / \mathrm{mL}$ w/v; $3 \mathrm{~mL} /$ aliquot) for $44.14,66.21,88.28,132.42,176.56$, $264.84,353.13,529.69,706.25,1059.38,1,412.50$ and $2,000.00 \mu \mathrm{g} / \mathrm{mL}$ of WSE were prepared by adding the corresponding volume of $66.21 \mu \mathrm{L}, 99.32 \mu \mathrm{L}, 132.42 \mu \mathrm{L}, 198.63 \mu \mathrm{L}, 264.84 \mu \mathrm{L}, 397.26$ $\mu \mathrm{L}, 529.70 \mu \mathrm{L}, 794.54 \mu \mathrm{L}, 1,059.38 \mu \mathrm{L}, 1,589.07 \mu \mathrm{L}, 2,118.75 \mu \mathrm{L}$ and $3,000 \mu \mathrm{L}$ of WSE from the stock respectively into $\leq 3.00 \mathrm{~mL}$ (i.e., $2,933.79$ to $0.00 \mu \mathrm{L}$ ) of the artificial seawater $(3.8 \% \mathrm{NaCl} / \mathrm{L}$ $\mathrm{w} / \mathrm{v}, \mathrm{pH}$ 8.0). For thrombolytic assay, $166.67 \mu \mathrm{L}$ of stock was directly added into the tubes $(\mathrm{n}=6 \times 3)$ containing $0.5 \mathrm{~mL}$ blood and filled up to $1.0 \mathrm{~mL}$ using NS $(\approx 333.33)$.

\subsection{Preparation of streptokinase (STK) stock}

The powder form of STK vial (1.5 million IU) was reconstituted and diluted by adding $5.0 \mathrm{~mL}$ of Solodex ${ }^{\mathrm{TM}}$ IV Infusion at the sidewall of the vial just immediately before the use. It was tilted, rolled gently until fully reconstituted. The stock concentration was $300,000 \mathrm{IU} / \mathrm{mL}$.

\subsection{Preparation of vincristine sulfate (VCF) solution}

The two VCF vials (Criston 2; $1 \mathrm{mg} / \mathrm{mL} ; 2 \mathrm{~mL} /$ vial) were further diluted by adding $2 \mathrm{~mL}$ of normal saline (NS; $0.9 \% \mathrm{NaCl}$ ) to each vial to get a $4 \mathrm{~mL}$ vial of $500 \mu \mathrm{g} / \mathrm{mL}$ of two stocks so that six consecutive concentrations $(500-15.625 \mu \mathrm{g} / \mathrm{mL})$ of aliquots $(4 \mathrm{~mL} /$ tube $)$ could be prepared and the stocks also left with $3 \mathrm{~mL} / \mathrm{vial}$ after dilution. The details of the dilution process have been described graphically in Fig. 4.

\subsection{Blood samples collection}

After having the prior consent, the whole fasting blood (WFB) sample $(5.0 \mathrm{~mL} / \mathrm{subject})$ of adult male (23-26 years old) was aseptically withdrawn in the morning (i.e., 8:00-8:15 am) after at least $12 \mathrm{hr}$ of fasting using a $5.0 \mathrm{~mL}$ syringe with a needle via venipuncture method (Simundic et al., 2018).

\subsection{Brine shrimp nauplii hatching \& collection}

The brine shrimp nauplii were hatched in $1 \mathrm{~L}$ of artificial seawater (i.e., $3.8 \% \mathrm{NaCl} / \mathrm{L} \mathrm{w} / \mathrm{v}$ ) prepared by adding 38 gram of unrefined sea salt into $1 \mathrm{~L}$ of distilled water in a beaker to which $2.5 \mathrm{~g}$ of 'S.K Artemia Cysts' was added., A $60 \mathrm{~W}$ bulb above the beaker (8"), single air-flow aeration pump and glass thermometer was fitted to maintain the light, the temperature at $28{ }^{\circ} \mathrm{C}$ and oxygen supply while the $\mathrm{pH}$ was 8 . The brine shrimp nauplii hatched after $24 \mathrm{hr}$ were immediate transfer to a freshly prepared media before drug exposure.

\subsection{Thrombolytic assay}


The in-vitro thrombolytic activity of WSE was performed using the methods described by (Prasad et al., 2006) with some minor modifications followed by the EFLM recommendations (Simundic et al., 2018). $0.5 \mathrm{~mL}$ of WFB sample from each subject in a triplicate manner for three different tests (i.e., NS, STK, and WSE) was transferred into the corresponding pre-weighed $(0.80 \pm 0.01 \mathrm{~g} / \mathrm{empty}$ tube) sterile collection tubes $(1.5 \mathrm{~mL})$ and were again weighed before incubation for 45 minutes at $37{ }^{\circ} \mathrm{C}$ to allow clot formation. After clot formation, the serum was gently aspirated and the weight of each of the 54 tubes $(n=6 \times 3 \times 3)$ containing blood clot was taken at room temperature $\left(24 \pm 2{ }^{\circ} \mathrm{C}\right)$ before NS, STK and WSE was added. Subsequently, $166.7 \mu \mathrm{L}$ of WSE from the stock was added into 18 respective tubes $(\mathrm{n}=6 \times 3)$. Similarly, $100 \mu \mathrm{L}$ of STK $(300,000 \mathrm{IU} / \mathrm{mL})$ and $500 \mu \mathrm{L}$ of NS $(0.9 \% \mathrm{NaCl})$ were added before incubation at $37{ }^{\circ} \mathrm{C}$ for 90 minutes and observed closely for clot lysis. After incubation, the lysate (i.e., upper phase) was discarded carefully and the weight of the tube containing the blood clot was recorded. The difference in clot weight before and after lysate formation was expressed as the percent of clot lysis (Fig. 1) using the following equation (1).

$$
\text { Clot lysis }(\%)=\frac{\text { (Weight of lysate })}{\text { (Weight of clot before lysis) }} \times 100
$$

Eq. 1

The weight of blood clot was calculated using the equation (2) as followed;

Weight of clot $(\mathrm{g})=$ Weight of tube containing blood clot - Weight of empty tube

Eq. 2

\subsection{Brine shrimp lethality (BSL) bioassay}

The BSL bioassay was carried based on the methods of (Meyer et al., 1982; Houghton et al., 1995; Cheikh-Rouhou et al., 2007; Gholamnezhad et al., 2016), with few modifications. 10 healthylooking immobilized nauplii (Babar et al., 2019a) along with $1 \mathrm{~mL}$ of media were transferred into each of the 57 glass test tubes labeled and prefilled with $1 \mathrm{~mL}$ of fresh media in advance. Then, 1 $\mathrm{mL}$ of WSE from each of the 12 aliquots, $1 \mathrm{~mL}$ of VCS from each of the 6 aliquots were added in triplicate manner. The volume was filled up to $5 \mathrm{~mL}$ using the seawater. The negative control contained only $5 \mathrm{~mL}$ seawater. The final log concentrations of VCS were from 100 to $3.125 \mu \mathrm{g} / \mathrm{mL}$ (Fig. 4). Finally, all the treated and control groups $(5 \mathrm{~mL} /$ test/tube) were incubated at room temperature $\left(26 \pm 1{ }^{\circ} \mathrm{C}\right)$ for $24 \mathrm{hr}(12 / 12$; light/dark cycle), the survived and died nauplii population was screened and counted using a handheld magnifying glass. The median lethal concentration (LC50) of the test samples was calculated from the linear regression equation of the scatter graph whilst the $\%$ of mortality was calculated by using the following equation (3):

$$
\% \text { Mortality }=\frac{(\text { Total no.of nauplii died/treatment })}{(\text { Total no.of nauplii used/treatment })} \times 100
$$

Eq. 3

\subsection{Data analysis}

The results are expressed as mean $\pm \mathrm{SD}$ and compared between treated and control groups, employing a Student's unpaired two-tailed $t$-test using GraphPad Prism 8 online. A p-value of less than 0.05 was considered statistically significant.

\section{Results and Discussion}

\subsection{Thrombolytic effect of WSE}

The exposure of a single, randomly selected WSE $(1666.67 \mu \mathrm{g} / \mathrm{mL})$ to healthy adult male human blood $(0.5 \mathrm{~mL} \times 3)$ against streptokinase (STK:72.41 $\pm 0.01 \%)$ of $30,000 \mathrm{IU} / \mathrm{mL}$ and normal saline (NS:3.76 $\pm 0.49 \%)$ has shown statistically significant ( $\mathrm{p}<0.0063 \& \mathrm{p}<0.0001) \%$ clot lysis by WSE $(90.00 \pm 0.02 \%)$ as shown in Fig. 1 . 


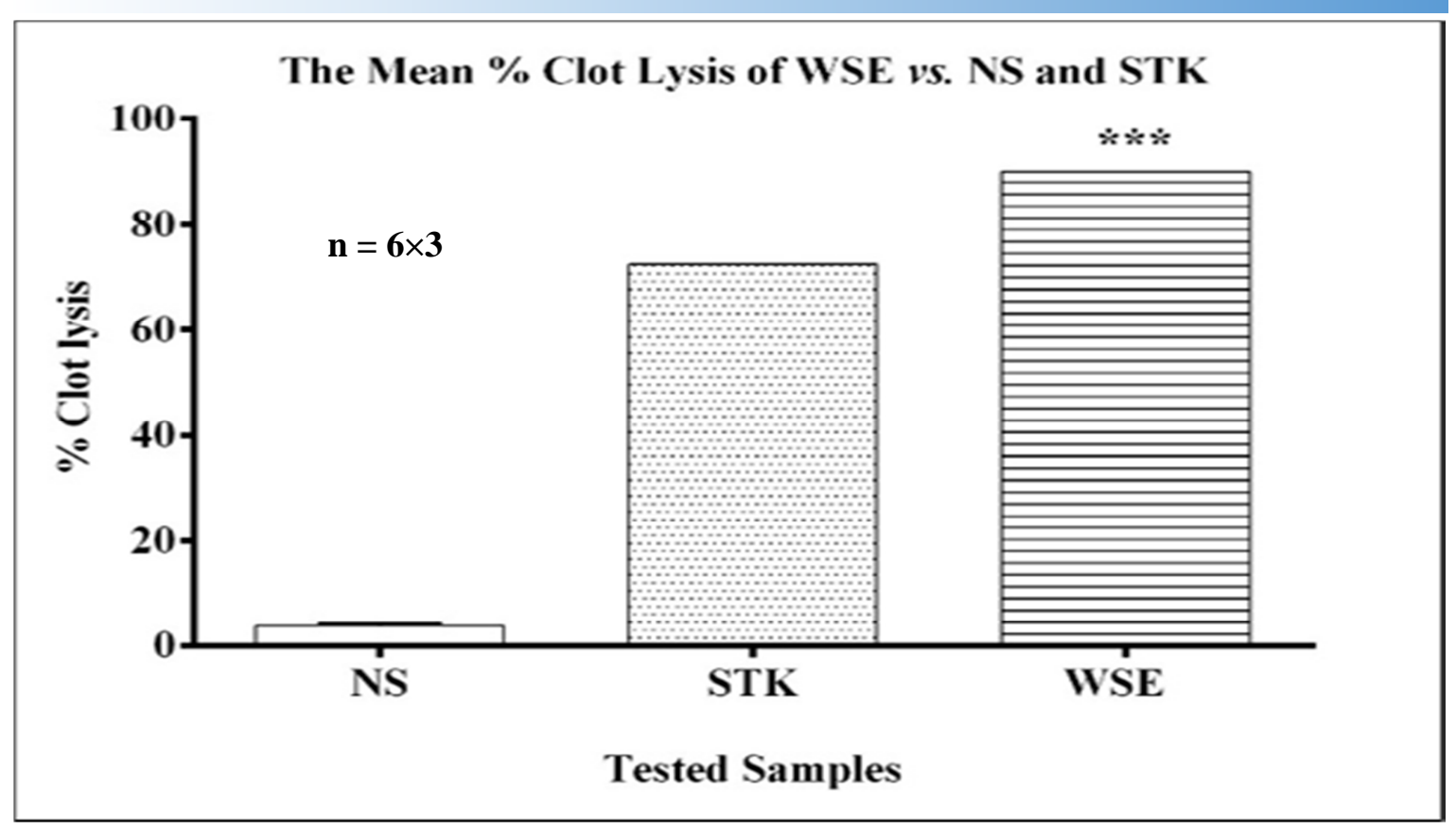

Fig 1. The mean $\%$ clot lysis \pm SD of WSE $(90 \pm 0.02 \%)$ after $24 \mathrm{hr}$ of exposure $v s$. normal saline, NS (3.76 $\pm 0.49 \%)$ and streptokinase, STK $(72.41 \pm 0.01 \%)$. Indicates the $\%$ clot lysis of WSE to be extremely statistically significant $(\mathrm{p}<0.0001) v s$. NS and $(\mathrm{p}<0.0063) v s$. STK.

\subsection{Cytotoxic effect of WSE}

The exposure of twelve randomly selected concentrations of WSE $(44.14,66.21,88.28,132.42$, 176.56, 264.84, 353.13, 529.69, 706.25, 1059.38, 1,412.50 and 2,000.00 $\mu \mathrm{g} / \mathrm{mL}$ ) to brine shrimp nauplii for 24 hours against the vincristine sulfate, VCS $\left(\operatorname{LC}_{50}=39.25 \mu \mathrm{g} / \mathrm{mL}\right)$ in artificial seawater $(3.8 \% \mathrm{NaCl} / \mathrm{L})$ has exhibited very mild cytotoxicity bearing $\mathrm{LC}_{50}=1795.90 \mu \mathrm{g} / \mathrm{mL}$ as shown in Fig. 2. The current result of WSE is about 46 times less potent than VCS, Fig.3. It is also found that the current LC50 of VCS is more than 8 times potent than a previous report $\left(\mathrm{LC}_{50}=0.33 \pm 0.055\right.$ $\mathrm{mg} / \mathrm{mL}$ ) made by (Rahmatullah et al., 2010).

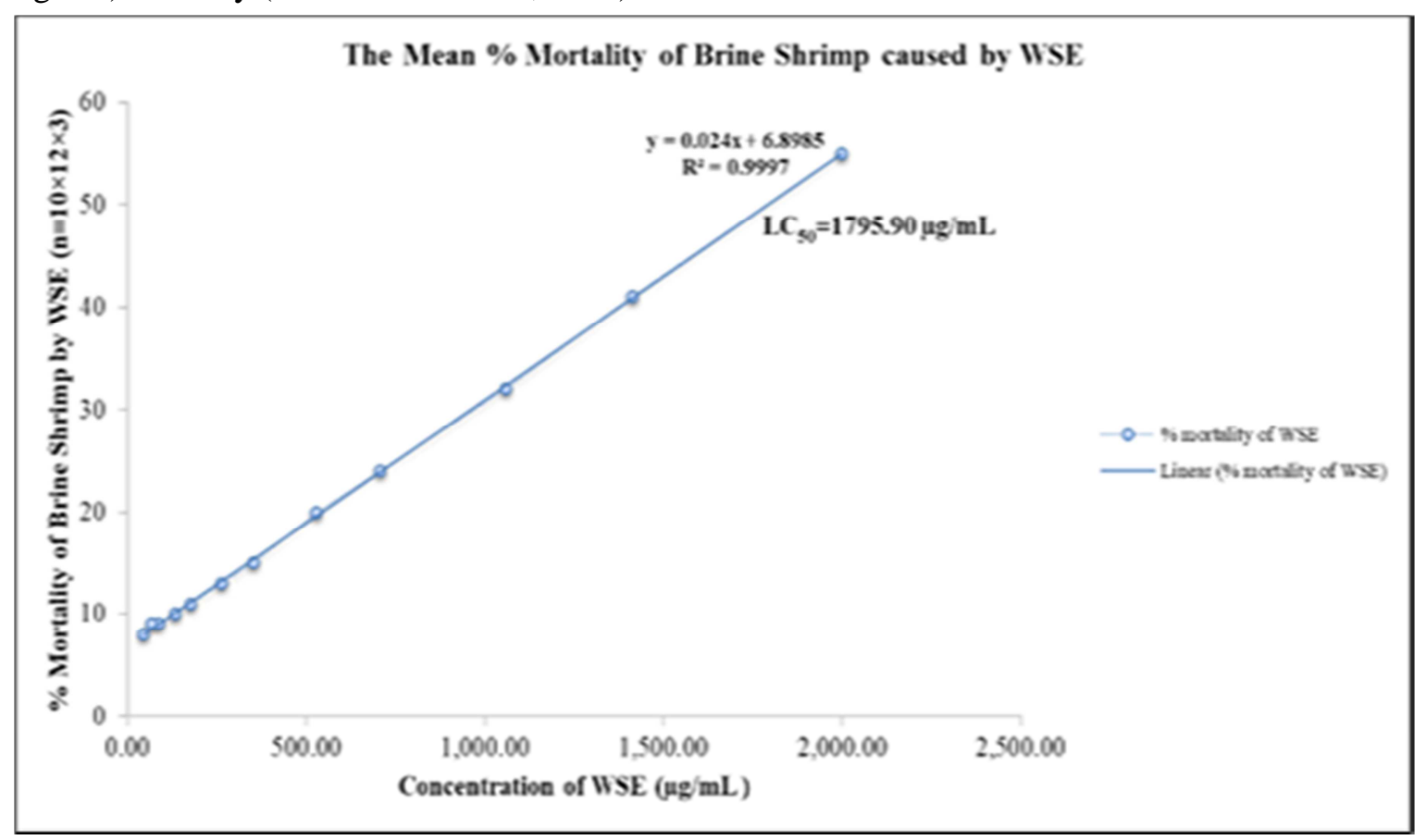

Fig 2. The mean $\%$ mortality of brine shrimp nauplii $(\mathrm{n}=10 \times 12 \times 3)$ caused by WSE of $44.14-2,000 \mu \mathrm{g} / \mathrm{mL}$ in triplicate manner, after $24 \mathrm{hr}$ of exposure at room temperature showing $\mathrm{LC}_{50}=1795.90 \mu \mathrm{g} / \mathrm{mL}$. 


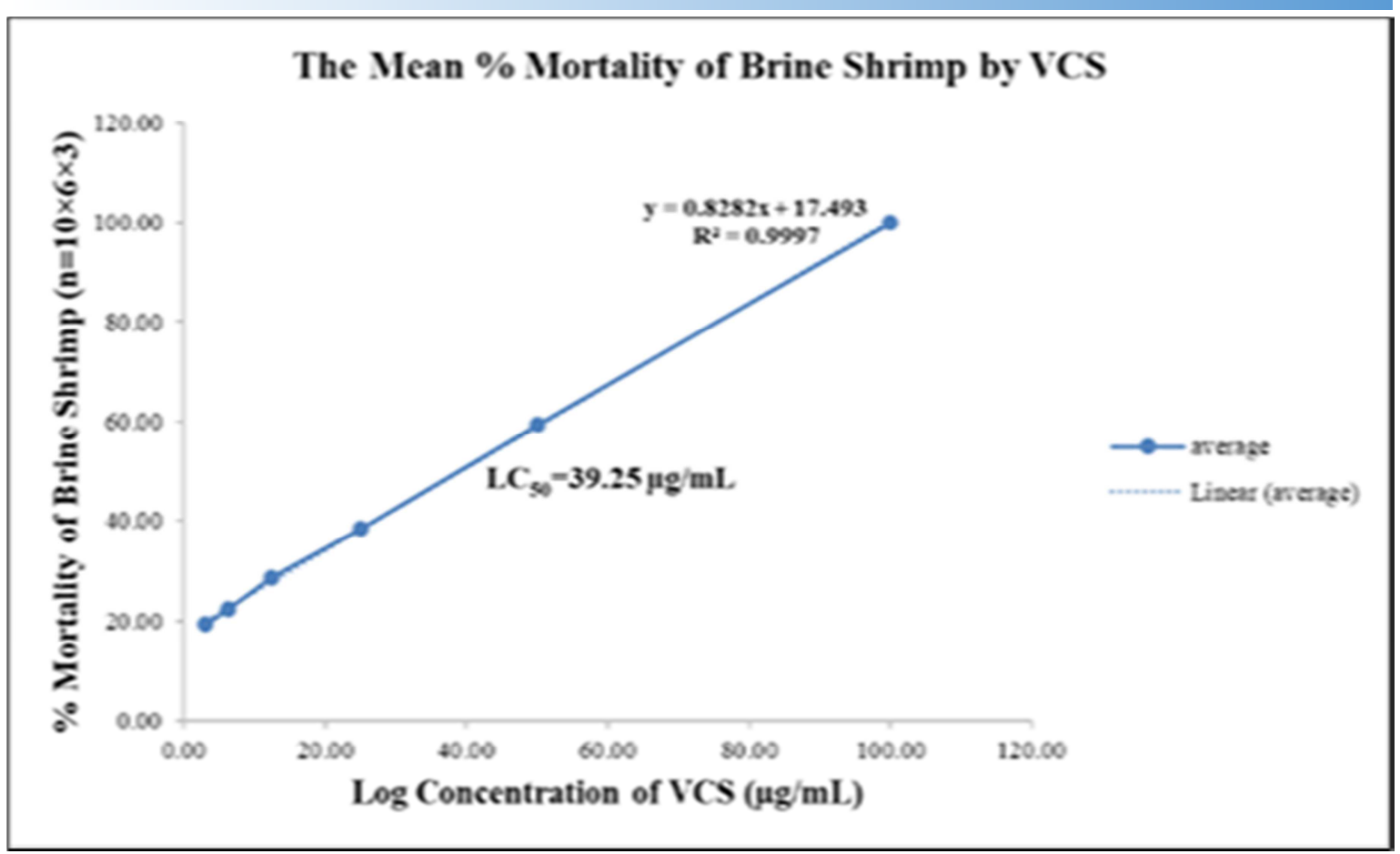

Fig 3. The mean $\%$ mortality of brine shrimp nauplii $(\mathrm{n}=10 \times 6 \times 3)$ caused by the VCS of $100-3.125 \mu \mathrm{g} / \mathrm{mL}$ in triplicate manner after $24 \mathrm{hr}$ of exposure at room temperature having $\mathrm{LC}_{50}=39.25 \mu \mathrm{g} / \mathrm{mL}$.

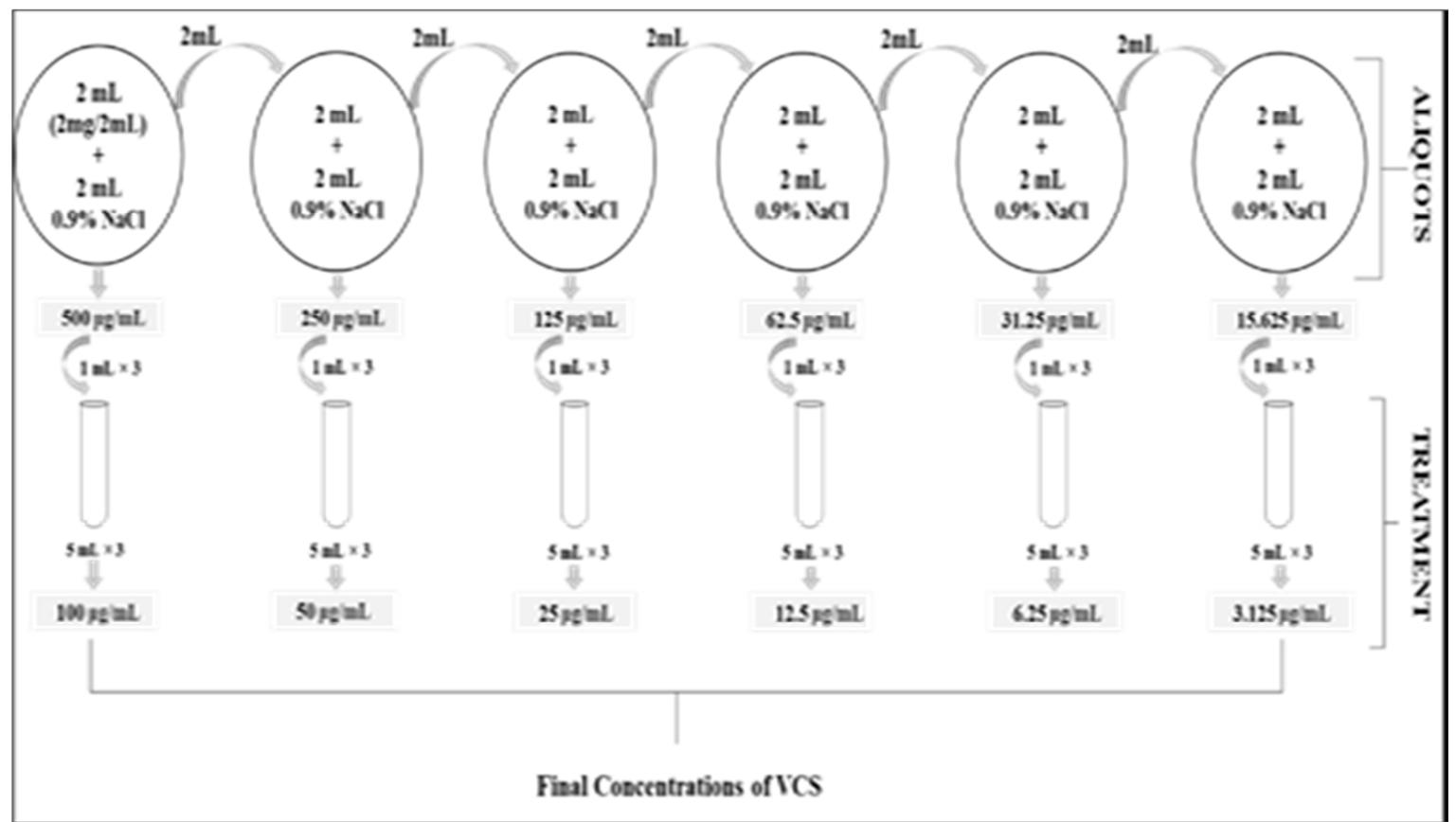

Fig 4. The preparation of six vincrestine sulfate (VCS) aliquots $(500-15.625 \mu \mathrm{g} / \mathrm{mL})(4 \mathrm{~mL} / \mathrm{aliquot})$ via serial dilution using normal saline (NS), and treatment $(5 \mathrm{~mL})$ concentrations $(100-3.125 \mu \mathrm{g} / \mathrm{mL})$ in triplicate manner.

\section{Conclusion}

It could be concluded that WSE has a potent thrombolytic effect with mild dose-dependent cytotoxicity towards brine shrimp nauplii (Artemia salina). It is also proposed that WSE might have a vital enzymatic role on thrombin, fibrin, and plasmin of blood which may involve serine proteases and protease-activated receptors (PARs). This pharmacological action of WSE is might 
be due to its antioxidant property, short-chain fatty acids, and/or amino acids. Further studies are highly recommended on the enzymatic role(s) and bioactive phytoconstituents of WSE.

\section{Acknowledgment}

All the authors are very grateful to the Department of Pharmacy, International Islamic University Chittagong (IIUC) for providing materials support and laboratory facilities. Special thanks should go to A. S. M Ali Reza (Asst. Prof.) and Mohammed Abu Sayeed (Assoc. Prof.), and the students who have volunteered in the thrombolytic study.

\section{References}

[1] Awad, E. M., \& Binder, B. R. (2005). In vitro induction of endothelial cell fibrinolytic alterations by Nigella sativa. Phytomedicine, 12(3), 194-202.

[2] Asgary, S., Najafi, S., Ghannadi, A., Dashti, G., \& Helalat, A. (2012). Efficiency of black cumin seeds on hematological factors in normal and hypercholesterolemic rabbits. ARYA atherosclerosis, 7(4), 146150 .

[3] Lebda, F. M., Bamosa, A. O., Kaatabi, H., Al Elq, A., \& Al-Sultan, A. (2012). Effect of Nigella sativa on hemodynamics, hemoglobin, and blood coagulation in patients with type 2 diabetes. The Egyptian Journal of Haematology, 37(2), 73-80.

[4] Ahmad, A., Husain, A., Mujeeb, M., Khan, S. A., Najmi, A. K., Siddique, N. A., ... \& Anwar, F. (2013). A review on therapeutic potential of Nigella sativa: A miracle herb. Asian Pacific journal of tropical biomedicine, 3(5), 337-352.

[5] Al-Jassir, M. S. (1992). Chemical composition and microflora of black cumin (Nigella sativa L.) seeds growing in Saudi Arabia. Food Chemistry, 45(4), 239-242.

[6] Houghton, P. J., Zarka, R., de las Heras, B., \& Hoult, J. R. S. (1995). Fixed oil of Nigella sativa and derived thymoquinone inhibit eicosanoid generation in leukocytes and membrane lipid peroxidation. Planta medica, 61(01), 33-36.

[7] Cheikh-Rouhou, S., Besbes, S., Hentati, B., Blecker, C., Deroanne, C., \& Attia, H. (2007). Nigella sativa L.: Chemical composition and physicochemical characteristics of lipid fraction. Food chemistry, 101(2), 673-681.

[8] Gholamnezhad, Z., Havakhah, S., \& Boskabady, M. H. (2016). Preclinical and clinical effects of Nigella sativa and its constituent, thymoquinone: A review. Journal of ethnopharmacology, 190, 372386.

[9] Babar, Z. M., Azizi, W. M., Ichwan, S. J., Ahmed, Q. U., Azad, A. K., \& Mawa, I. (2019a). A simple method for extracting both active oily and water soluble extract (WSE) from Nigella sativa (L.) seeds using a single solvent system. Natural product research, 33(15), 2266-2270.

[10] Babar, Z. M., Jaswir, I., Tareq, A. M., Ali Reza, A. M., Azizi, W. M., Hafidz, M., ... \& Ichwan, S. J. (2019b). In vivo anxiolytic and in vitro anti-inflammatory activities of water-soluble extract (WSE) of Nigella sativa (L.) seeds. Natural Product Research, 1-6.

[11] Dewan, S. M. R., \& Das, A. (2013). Investigation of in vitro thrombolytic potential and phytochemical nature of Crinum latifolium L. leaves growing in coastal region of Bangladesh. Int J Bio Pharm Res, $4(1), 1-7$.

[12] Ali, M., Salim Hossain, M., Islam, M., Arman, S. I., Sarwar Raju, G., Dasgupta, P., \& Noshin, T. F. (2014). Aspect of thrombolytic therapy: a review. The Scientific World Journal, 2014.

[13] Tanaka, K. A., Key, N. S., \& Levy, J. H. (2009). Blood coagulation: hemostasis and thrombin regulation. Anesthesia \& Analgesia, 108(5), 1433-1446.

[14] Chapin, J. C., \& Hajjar, K. A. (2015). Fibrinolysis and the control of blood coagulation. Blood reviews, 29(1), 17-24. 
[15] Mahmoudvand, H., Sharififar, F., Assadipour, A., Hassan Moshafi, M., \& Alishahi, F. (2017). Bioassay Screening of the Essential Oil and Various Extracts of Nigella sativa L. Seeds Using Brine Shrimp Toxicity Assay. Herbal Medicines Journal, 2(1), 26-31.

[16] Rahmatullah, M., Sadeak, S. M. I., Bachar, S. C., Hossain, M. T., Abdullah-al-Mamun, M., Jahan, N., ... \& Rahman, S. (2010). Brine shrimp toxicity study of different Bangladeshi medicinal plants. Advances in Natural and Applied Sciences, 4(2), 163-173.

[17] Simundic, A. M., Bölenius, K., Cadamuro, J., Church, S., Cornes, M. P., van Dongen-Lases, E. C., ... \& Hoke, R. (2018). Joint EFLM-COLABIOCLI Recommendation for venous blood sampling. Clinical Chemistry and Laboratory Medicine (CCLM), 56(12), 2015-2038.

[18] Prasad, S., Kashyap, R. S., Deopujari, J. Y., Purohit, H. J., Taori, G. M., \& Daginawala, H. F. (2006). Development of an in vitro model to study clot lysis activity of thrombolytic drugs. Thrombosis Journal, 4(1), 14.

[19] Meyer, B. N., Ferrigni, N. R., Putnam, J. E., Jacobsen, L. B., Nichols, D. J., \& McLaughlin, J. L. (1982). Brine shrimp: a convenient general bioassay for active plant constituents. Planta medica, 45(05), 31-34.

[20] Distel, M., \& Köster, R. W. (2007). In vivo time-lapse imaging of zebrafish embryonic development. CSH Protoc, 2007. 